\title{
Geltungserhaltende Reduktion
}

\author{
Richterliche Ersatzregelbildung im schweizerischen Vertragsrecht
}

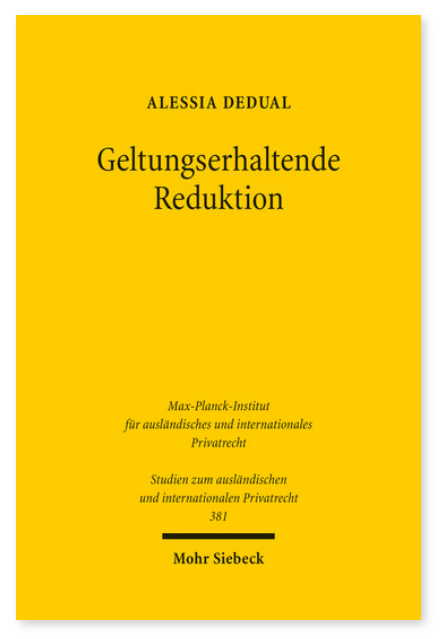

2017. XX, 313 Seiten. StudIPR 381

ISBN 978-3-16-155276-2

DOI 10.1628/978-3-16-155276-2

eBook PDF $69,00 €$

ISBN 978-3-16-155275-5

fadengeheftete Broschur 69,00€
Der Begriff 'geltungserhaltende Reduktion' steht im kontinentaleuropäischen Diskurs für eine komplexe Rechtsfigur im Graubereich von Auslegung, richterlicher Rechtsfortbildung und Vertragsanpassung. Im Kern bezeichnet der Ausdruck nämlich die Rückführung einer rechtswidrigen und deswegen an sich unwirksamen vertraglichen Vereinbarung auf eine noch zulässige Gestaltung. Tief in der schweizerischen Rechtskultur verwurzelt, wird die geltungserhaltende Reduktion in Deutschland seit langem mehrheitlich verworfen. Bislang war diese Diskussion vor allem geprägt von Überlegungen zur Reichweite der gerichtlichen Vertragsinhaltskontrolle Allgemeiner Geschäftsbedingungen und der normativen Verbindlichkeit des Parteiwillens. Alessia Dedual fragt aus einer regulierungstheoretischen Perspektive nach den Möglichkeiten und Grenzen der geltungserhaltenden Reduktion vor allem im Zusammenhang der schweizerischen Rechtsordnung. Dabei verbindet sie ökonomische Theorieansätze mit dogmatischer Rekonstruktion und kann auf diese Weise Lösungsvorschläge entwickeln, die über das schweizerische Privatrecht hinausreichen.

Die Arbeit wurde 2018 sowohl von der Rechtswissenschaftlichen Fakultät der Universität Zürich mit dem Issekutz Preis für hervorragende Leistungen im Bereich des Wirtschaftsrechts als auch mit dem Prof. Walter Hug Preis ausgezeichnet. Zursätzlich wurde die herausragende Arbeit mit dem Mercator Award 2019 der Universität Zürich ausgezeichnet.

Alessia Dedual Geboren 1987; Studium der Rechtswissenschaft an der Universität Zürich; Doktoratsstudium an der Universität Zürich und der Humboldt-Universität zu Berlin; Assistentin am Lehrstuhl für Rechtsgeschichte, Kirchenrecht, Rechtstheorie und Privatrecht an der Universität Zürich; Forschungsaufenthalte an der Humboldt Universität zu Berlin und am Max Planck-Institut zur Erforschung von Gemeinschaftsgütern, Bonn; Assistentin am Lehrstuhl für Römisches Recht, Privatrecht und Rechtsvergleichung an der Universität Zürich.

Jetzt bestellen:

https://mohrsiebeck.com/buch/geltungserhaltende-reduktion-9783161552762?no_cache=1

order@mohrsiebeck.com

Telefon: $+49(0) 7071-923-17$

Telefax: $+49(0) 7071-51104$ 